\title{
Relationship of cervical ectopy to chlamydia infection in young women
}

\author{
Vincent Lee, Jean M Tobin, Elizabeth Foley
}

\section{Abstract}

Objective Genital Chlamydia trachomatis infection is the most common bacterial sexually transmitted infection (STI) in the UK. Behaviours including multiple sex partners and inconsistent condom use, and biological factors such as cervical ectopy, may increase susceptibility to STIs. Cervical ectopy is thought to increase risk of chlamydia infection by exposing columnar epithelium to a potential infectious inoculum. This study aimed to determine whether chlamydia was more prevalent in young women with cervical ectopy.

Methods Clinical notes of women aged 16-24 years attending the Portsmouth Genitourinary Medicine Clinic for an STI screen during the period May-July 2003 were reviewed retrospectively. Information collected included the presence or absence of cervical ectopy, smoking habits, methods of contraception, number of sexual partners in the previous 3 months, and previous STIs. Chlamydia infection was diagnosed by using strand displacement amplification on cervical swabs.

Results A total of 231 women were included in the study. The mean age was 19.8 years. Evidence of cervical ectopy was found in 107 women. Chlamydial infection was detected in $37.4 \%(40 / 107)$ of those women with cervical ectopy and $21.8 \%(27 / 124)$ in those without cervical ectopy. This difference was statistically significant $(p=0.009)$. The significance remained even when accounting for confounding variables.

Conclusions Cervical ectopy is a common physiological process in young women. Recognition of cervical ectopy should alert the clinician to the possibility of a genital chlamydia infection. Opportunistic screening for chlamydia in young people should be offered to reduce the prevalence of infection and its sequelae.

J Fam Plann Reprod Health Care 2006; 32(2): 104-106 (Accepted 4 January 2006)

\section{Key message points}

- Genital Chlamydia trachomatis infection is the most common bacterial sexually transmitted infection in the UK.

- A diagnosis of chlamydia is more likely in young women with cervical ectopy.

- Opportunistic screening for chlamydia in young people should be offered to reduce the prevalence of infection and its sequelae.

Department of Genitourinary Medicine, Royal South Hants Hospital, Southampton, UK

Vincent Lee, MRCP, Dip GUM, Consultant

Elizabeth Foley, MRCOG, DFFP, Consultant

Department of Genitourinary Medicine, St Mary's Hospital, Portsmouth, UK

Jean M Tobin, FRCOG, MFFP, Consultant

Correspondence to: Dr Vincent Lee, Manchester Centre for Sexual Health, Manchester Royal Infirmary, Oxford Road,

Manchester M13 9WL, UK. E-mail: Vincent.lee@cmmc.nhs.uk

\section{Introduction}

Genital Chlamydia trachomatis infection is the most common bacterial sexually transmitted infection (STI) in the UK. Previous studies ${ }^{1-4}$ have reported highest rates in the under-25-year-old age group. Adolescent behavioural risks for STIs include multiple sex partners and inconsistent condom use. Biological factors that may increase susceptibility include cervical ectopy.

Cervical ectopy is a common physiological process that can occur in adolescence, during pregnancy and in response to hormonal contraceptive pills. Cervical ectopy is thought to increase risk of chlamydia infection by exposing columnar epithelium to a potential infectious inoculum. It has previously been suggested that cervical ectopy is a possible risk factor for chlamydial infection. ${ }^{5-13}$

The aim of the present study was to determine whether chlamydia was more prevalent in young women with cervical ectopy.

\section{Methods}

Women aged 16-24 years attending the Portsmouth Genitourinary Medicine (GUM) Clinic for an STI screen during the period May-July 2003 were included in the study. All health care providers involved in the study were experienced in recognising cervical ectopy. The presence or absence of cervical ectopy was documented. The notes were reviewed retrospectively and the presence of cervical ectopy, smoking habits and methods of contraception were correlated with chlamydial infection. Chlamydia infection was diagnosed by using strand displacement amplification on cervical swabs.

Table 1 Baseline characteristics of the 231 study participants

\begin{tabular}{|c|c|c|}
\hline Characteristic & $\begin{array}{l}\text { Cervical ectopy } \\
\text { present }\end{array}$ & $\begin{array}{l}\text { Cervical ectopy } \\
\text { absent }\end{array}$ \\
\hline Patients $[n,(\%)]$ & $107(46.3)$ & $124(53.7)$ \\
\hline \multicolumn{3}{|l|}{ Age (years) } \\
\hline Mean & 20.1 & 19.9 \\
\hline Median & 20 & 20 \\
\hline Range & $16-24$ & $16-24$ \\
\hline \multicolumn{3}{|c|}{ Sexual partners in last 3 months $(n)$} \\
\hline 1 & 73 & 96 \\
\hline 2 & 30 & 26 \\
\hline 3 & 4 & 2 \\
\hline \multicolumn{3}{|l|}{ Previous STIs $(n)$} \\
\hline None & 102 & 105 \\
\hline Chlamydia & 3 & 15 \\
\hline Gonorrhoea & 0 & 1 \\
\hline Genital warts & 1 & 4 \\
\hline Genital herpes & 1 & 1 \\
\hline Smoking $[n,(\%)]$ & $39(36.4)$ & $39(31.4)$ \\
\hline Previous pregnancy $[n,(\%)]$ & $20(18.7)$ & $31(25.0)$ \\
\hline \multicolumn{3}{|l|}{ Contraception $[n,(\%)]$} \\
\hline None & $10(9.4)$ & $11 \quad(8.9)$ \\
\hline $\mathrm{OCP}$ & $75(70.1)$ & $76(61.3)$ \\
\hline Condom & $9(8.4)$ & $17(13.7)$ \\
\hline DMPA & $7(6.5)$ & $17(13.7)$ \\
\hline IUD & $6(5.6)$ & $3(2.4)$ \\
\hline Chlamydia positive $[n,(\%)]$ & $40(37.4)$ & $27(21.8)$ \\
\hline
\end{tabular}

DMPA, depot medroxyprogesterone acetate; IUD, intrauterine device; OCP, oral contraceptive pill; STI, sexually transmitted infection. 


\begin{tabular}{|c|c|c|c|c|c|}
\hline \multirow[t]{2}{*}{ Characteristic } & \multirow[t]{2}{*}{ Total $(n)$} & \multicolumn{3}{|c|}{ Chlamydia prevalence } & \multirow[t]{2}{*}{ OR $(95 \% \mathrm{CI})$} \\
\hline & & $n$ & $\%$ & $p$ & \\
\hline \multicolumn{6}{|l|}{ Age (years) } \\
\hline $16-18$ & 64 & 19 & 29.7 & & \\
\hline $19-21$ & 109 & 30 & 27.5 & & \\
\hline $22-24$ & 58 & 18 & 31.0 & & \\
\hline \multicolumn{6}{|c|}{ Partners in last 3 months (n) } \\
\hline 1 & 169 & 42 & 24.9 & & $2.04(1.05-3.94)$ \\
\hline$>1$ & 62 & 25 & 40.3 & 0.027 & \\
\hline \multicolumn{6}{|l|}{ Previous STI } \\
\hline None & 207 & 60 & 29.0 & & \\
\hline Chlamydia & 17 & 4 & 23.5 & 0.63 & \\
\hline \multicolumn{6}{|l|}{ Smoking } \\
\hline Yes & 78 & 22 & 28.2 & 0.84 & \\
\hline No & 153 & 45 & 29.4 & & \\
\hline \multicolumn{6}{|c|}{ Previous pregnancy } \\
\hline Yes & 51 & 19 & 37.3 & & \\
\hline No & 180 & 48 & 26.7 & 0.14 & \\
\hline \multicolumn{6}{|l|}{ Cervical ectopy } \\
\hline Yes & 107 & 40 & 37.4 & 0.0009 & $2.14(1.16-4.00)$ \\
\hline No & 124 & 27 & 21.8 & & \\
\hline \multicolumn{6}{|l|}{ Contraception } \\
\hline None & 21 & 5 & 23.8 & & \\
\hline Condom & 26 & 10 & 38.5 & 0.74 & \\
\hline IUD & 9 & 3 & 33.3 & & \\
\hline OCP & 151 & 41 & 27.2 & & \\
\hline DMPA & 24 & 8 & 33.3 & & \\
\hline
\end{tabular}

DMPA, depot medroxyprogesterone acetate; IUD, intrauterine device; OCP, oral contraceptive pill; OR, odds ratio; STI, sexually transmitted infection.

\section{Results}

A total of 231 women were included in the study. The mean age was 19.8 years. Evidence of cervical ectopy was found in 107 women. Six were non-Caucasians. The baseline characteristics are shown in Table 1.

We evaluated the independent contribution of smoking, previous STIs and previous pregnancy. Previous studies 5,7 suggested that oral contraceptive pills might promote chlamydial infection of the cervix. The present study, however, showed no significant difference between different contraceptive methods (Table 2). There is a trend towards an increase in chlamydia diagnosis in women using condoms. As with previous studies, ${ }^{9,13-15}$ chlamydial infection was more common in women with more sexual partners in the previous 3 months.

Chlamydial infection was detected in $37.4 \%(40 / 107)$ of those women with cervical ectopy and $21.8 \%$ (27/124) in those without cervical ectopy. This difference was statistically significant $(p=0.009)$. The significance remained even when accounting for confounding variables. One patient was found to have concurrent gonorrhoea.

\section{Discussion}

In 1998, the Department of Health in England funded a pilot opportunistic chlamydia screening programme in Wirral and Portsmouth. Prevalence of genital chlamydia infection diagnosed in GUM clinics was similar to those in other health care settings. Awareness of genital chlamydia infection and its consequences if left untreated were raised after the pilot study. In recent years, young women attend GUM clinics for sexual health screening because in most areas this is the main or only place where screening for all STIs is undertaken. With more widespread availability of screening, women presenting without symptoms have much the same rate of STIs wherever they are tested.

The present study shows that a diagnosis of chlamydia is more likely in young women with cervical ectopy. To assay for chlamydia we used a nucleic acid amplification technique test with higher sensitivity than the enzyme immunosorbent assay methods used previously. ${ }^{16}$
The relationship between oral contraceptive use and chlamydia has been debated. The present data show there is no increased risk of chlamydial infection in women taking the contraceptive pill. Although the oral contraceptive pill has been associated with the presence of cervical ectopy, there was no significant difference in the proportion of women with cervical ectopy with any contraceptive method in this study. Use of condoms is advocated to prevent the acquisition of STIs. It is surprising that in the present study more women using condoms as their contraceptive method had chlamydia infection. Adolescents frequently change or discontinue contraception, have variable compliance with any contraceptive method, and change the frequency of intercourse. We did not assess the consistency of condom use that may account for the results.

No previous studies have been done to determine whether chlamydial infection caused cervical ectopy. Both genital chlamydial infection and cervical ectopy are common in young women. We designed the present study to assess whether young women with an ectopy were more likely to have chlamydia, among other reasons as a potential aid to diagnosis by alerting clinicians to the possibility of infection.

In the present study, women with a previous pregnancy were found to have more genital chlamydia infection but less ectopy than those without a previous pregnancy. This finding is not statistically significant and may be due to demographic features such as being in a stable relationship with the father of the child. We did not design the study to examine the relationship between pregnancy and chlamydia; a further study would be needed to investigate this aspect.

In conclusion, cervical ectopy is a common physiological process in young women. Young people are at increased risk for chlamydial infection. Opportunistic screening for chlamydia in young people should be offered to reduce the prevalence of infection and its sequelae. Recognition of cervical ectopy should alert the clinician to the possibility of a genital chlamydia infection. 
Statements on funding and competing interests

Funding. None identified.

Competing interests. None identified.

References

1 Fenton KA, Korovessis C, Johnson AM, McCadden A, McManus S, Wellings $\mathrm{K}$, et al. Sexual behaviour in Britain: reported sexually transmitted infections and prevalent genital Chlamydia trachomatis infection [see Comment]. Lancet 2001; 358(9296): 1851-1854 [erratum in Lancet 2002; 359(9301): 174].

2 Health Protection Agency, SCIEH, ISD, National Public Health Service for Wales, CDSC Northern Ireland and the UASSG. Renewing the Focus. HIV and Other Sexually Transmitted Infections in the United Kingdom in 2002. London, UK: Health Protection Agency, 2003.

3 Health Protection Agency. Sexually transmitted infections quarterly report: an update on genital chlamydial infections in the United Kingdom, and efforts to improve screening services. CDR Weekly 2004; 14(5).

4 Pimenta JM, Catchpole M, Rogers PA, Hopwood J, Randall S, Mallinson $\mathrm{H}$, et al. Opportunistic screening for genital chlamydial infection. II: Prevalence among healthcare attenders, outcome, and evaluation of positive cases [see Comment]. Sex Transm Infect 2003; 79: 22-27 [erratum in Sex Transm Infect 2004; 80: 156].

5 Arya OP, Mallinson H, Goddard AD. Epidemiological and clinical correlates of chlamydial infection of the cervix. Br J Vener Dis 1981; 57: $118-124$.

6 Dowe G, Smikle M, King SD, Wynter H, Frederick J, Hylton-Kong T. High prevalence of genital Chlamydia trachomatis infection in women presenting in different clinical settings in Jamaica: implications for control strategies [see Comment]. Sex Transm Infect 1999; 75: 412-416.

7 Fish AN, Fairweather DV, Oriel JD, Ridgway GL. Chlamydia trachomatis infection in a gynaecology clinic population: identification of high-risk groups and the value of contact tracing. Eur J Obstet Gynecol Reprod Biol 1989; 31: 67-74

8 Harrison HR, Costin M, Meder JB, Bownds LM, Sim DA, Lewis M, et al. Cervical Chlamydia trachomatis infection in university women: relationship to history, contraception, ectopy, and cervicitis. Am J Obstet Gynecol 1985; 153: 244-251.

9 Kovacs GT, Westcott M, Rusden J, Asche V, King H, Haynes SE, et al. The prevalence of Chlamydia trachomatis in a young, sexually active population. Med J Aust 1987; 147(11-12): 550-552.

10 Quinn TC Gaydos C, Shepherd M, Bobo L, Hook EW 3rd, Viscidi R, et al. Epidemiologic and microbiologic correlates of Chlamydia trachomatis infection in sexual partnerships. JAMA 1996; 276: 1737-1742.

11 Sedlecki K, Markovic M, Rajic G. Risk factors for chlamydia infections of the genital organs in adolescent females [in Serbian]. Srp Arh Celok Lek 2001; 129(7-8): 169-174.

12 Stergachis A, Scholes D, Heidrich FE, Sherer DM, Holmes KK, Stamm WE. Selective screening for Chlamydia trachomatis infection in a primary care population of women. Am J Epidemiol 1993; 138: $143-153$

13 Jacobson DL, Peralta L, Farmer M, Graham NM, Gaydos C, Zenilman J. Relationship of hormonal contraception and cervical ectopy as measured by computerized planimetry to chlamydial infection in adolescents. Sex Transm Dis 2000; 27: 313-319.

14 Chacko MR, Lovchik JC. Chlamydia trachomatis infection in sexually active adolescents: prevalence and risk factors. Pediatrics 1984; 73: 836-840.

15 Rahm VA, Odlind V, Pettersson R. Chlamydia trachomatis in sexually active teenage girls. Factors related to genital chlamydial infection: a prospective study. Genitourin Med 1991; 67: 317-321.

16 Watson EJ, Templeton A, Russell I, Pavonen J, Mardh PA, Stary A, et al. The accuracy and efficacy of screening tests for Chlamydia trachomatis: a systematic review. J Med Microbiol 2002; 51: 1021-1031

\section{vasectomy services}

\section{Over 100,000 men have chosen us...}

making Marie Stopes International the country's most experienced vasectomy provider. With 20 centres nationwide we are able to offer a quick, reliable and straightforward service with no waiting lists.

For men who want the convenience of counselling, assessment and procedure on one day we offer a same day service. Our "non scalpel vasectomy technique" takes just a few minutes with no stitches and we provide all post operative aftercare and semen testing.

If you or your patient would like more information, simply call the number below and we will send further details.

Call us on 08451203644 - 24 hours or visit www.mariestopes.org.uk

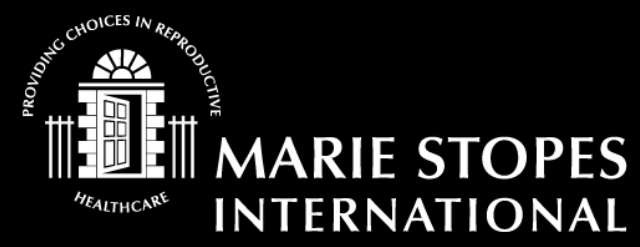

